\title{
Makna Penebusan Dalam Upacara Tiwah Sebagai Pendekatan Kontekstualisasi Injil
}

\author{
Ruat Diana ${ }^{1}$, Sabda Budiman², Maharin ${ }^{3}$ \\ Sekolah Tinggi Teologi Simpson Ungaran \\ Email: dianadarmawan@gmail.com¹, sabdashow99@gmail.com² ${ }^{2}$ balin07101990@gmail.com³
}

\begin{abstract}
Culture in Hindu Kaharingan, namely Tiwah culture is a form of culture with a unique ceremony. In the process of implementation, tiwah ceremony contains a procession that is diverse and full of meaning. Through the meaning of this tiwah ceremony, the author adopted it as a contextualization medium to convey the gospel. The author seeks to understand the meaning and then bring up Christ in the tiwah ceremony performed by kaharingan Hindus. Using a descriptive qualitative approach and observing the implementation of tiwah ceremony through interviews and literature, the author examines the meaning in the Tiwah ceremony which is then filtered by the method of adopting, changing, and fruiting and the word of God as the benchmark. Jesus as a sacrifice in the tiwah ceremony, Jesus as the way to "Lewu Tatau", and Jesus as a mediator between man and "Ranying Hatalla". These points became the result of discussion in the contextualization approach of the Gospel in the Tiwah ceremony.
\end{abstract}

Keywords: tiwah ceremony, Hindu Kaharingan, meaning, contextualization

\begin{abstract}
Abstrak
Budaya dalam agama Hindu Kaharingan, yaitu budaya Tiwah merupakan sebuah bentuk budaya yang dengan pelaksanaan upacara yang unik. Dalam proses pelaksanaannya, upacara tiwah mengandung prosesi yang beragam dan penuh makna. Melalui makna upacara tiwah ini, penulis mengadopsikannya sebagai media kontekstualisasi untuk menyampaikan Injil. Penulis berusaha memahami makna dan kemudian memunculkan Kristus dalam upacara tiwah yang dilakukan oleh umat Hindu Kaharingan. Dengan menggunakan pendekatan kualitatif deskriptif serta mengamati pelaksanaan upacara Tiwah melalui wawancara dan literatur yang ada, penulis mengkaji makna dalam upacara Tiwah tersebut yang kemudian disaring dengan metode mengadopsi, mengubah, dan membuah dan firman Tuhan sebagai tolak ukurnya. Yesus sebagai korban dalam upacara tiwah, Yesus sebagai jalan menuju "Lewu Tatau", dan Yesus sebagai pengantara antara manusia dan "Ranying Hatalla". Poin-poin tersebut menjadi hasil pembahasan dalam pendekatan kontekstualisasi Injil dalam upacara Tiwah.
\end{abstract}

Kata Kunci: upacara tiwah, Hindu Kaharingan, makna, kontekstualisasi

\section{Pendahuluan}

Kaharingan berasal dari kata bahasa Sangiang (Dayak Kuno) "Haring" yang artinya Hidup. Kemudian mendapat awalan "Ka" dan akhirannya "An" menjadi "Kaharingan". Selain itu, Kaharingan juga dapat diartikan dengan kehidupan yang abadi dari Ranying Hatalla Langit. Kemudian dalam bahasa Sangiang, Kaharingan berarti "hidup atau

\footnotetext{
${ }^{1}$ Agung Nugraha, Rindu Ladang: Perspektif Perubahan Masyarakat Desa Hutan (Tangerang: Wana Aksara, 2009), 129.
} 
kehidupan”. Sedangkan dalam bahasa dayak Ngaju sehari-hari, Kaharingan diartikan sebagai "ada dengan sendirinya". 2 Jadi Kaharingan dapat diartikan sebagai 'Kehidupan' yang abadi dari Ranying Mahatalla Langit untuk menuju pada kesempurnaan hidup yang sempurna dari makna tersebut sehingga muncullah tradisi asli Dayak, yang masih sangat kental dalam pelaksanaan upacara ritual keagamaannya.

Pada mulanya agama Kaharingan merupakan agama (atau lebih tepatnya ialah kepercayaan) yang dianut oleh suku dayak Ngaju. Namun pada saat ini, agama Kaharingan di anut oleh masyarakat dayak yang berada di Kalimantan Tengah, Selatan, Timur, dan Barat. Di Kalimantan Selatan, suku dayak yang menganut agama Kaharingan adalah dayak Meratus. Di Kalimantan Timur adalah suku dayak Tunjung Benuaq. Di Kalimantan Tengah adalah dayak Ngaju, dayak Luangan, Ma'Anyan, Tumon, dan Siang. Jadi suku-suku dayak inilah yang masih berpegang pada Agama tersebut. Di daerah Kalimantan Barat adalah dayak Ot Danum di Ambalau dan Serawai. Penyebaran agama Kaharingan yang beraasalnya dari suku dayak Ngaju ini dikarenakan suku dayak lainnya ingin mendapat "paying politik", sehingga suku dayak lainnya seperti suku dayak Luangan dan Ma'anyan, yang sebelumnya telah memiliki kepercayaan tersendiri, rela disebut dan menyebut dirinya Kaharingan. ${ }^{3}$

Kaharingan adalah religi suku atau kepercayaan tradisional suku Dayak di Kalimantan. Istilah kaharingan artinya tumbuh atau hidup seperti dalam istilah danum kaharingan (air kehidupan), maksudnya agama suku atau kepercayaan terhadap Tuhan Yang Maha Esa (Ranying), yang hidup dan tumbuh secara turun temurun, dan dihayati oleh suku dayak Kalimantan, ketika pemerintah Indonesia mewajibkan penduduk dan warganegara untuk menganut salah satu agama yang diakui oleh pemerintah republik Indonesia ${ }^{4}$. Karena Oleh sebab itu kepercayaan kaharingan dan religi suku yang lain telah dimasukan dalam kategori agama Hindu sejak 20 April 1980 mengingat adanya persamaan dalam penggunaan sarana kehidupan melaksanakan ritual untuk korban untuk mencapai Tuhan Yang Maha Esa. Pada Tahun 1944, kaharingan diperkenalkan oleh Tjilik Ruwut saat ia menjabat Residen Sampit yang berkedudukan di Banjarmasin. Tahun 1945, pendudukan Jepang mengajukan Kaharingan sebagai penyebutan agama Dayak. Tahun 1950, dalam kongres serikat Kaharingan Dayak Indonesia, Kaharingan resmi dipakai sebagai generik untuk agama dayak. ${ }^{5}$

Sementara pada tahun 1980, para penganutnya berintegrasi dengan Hindu, menjadi Hindu Kaharingan. Pemilihan integrasi ke Hindu ini bukan karena kesamaan ritual, tetapi dikarenakan Hindu adalah agama tertua di Kalimantan. Lambat laun Kaharingan menjadi

\footnotetext{
${ }^{2}$ Nasruddin, dkk.,Kearifan Lokal Di Tengah Modernisasi (Jakarta: Pusat Penelitian dan Pengembangan Kebudayaan Badan Pengembangan Sumber Daya Kebudayaan dan Pariwisata Kementerian Kebudayaan dan Pariwisata Republik Indonesia, 2011), 94. 2009), 3 .

${ }^{3}$ Marko Mahin, "Kaharingan: Dinamika Agama Dayak Di Kalimantan Tengah" (Universitas Indonesia,

${ }^{4}$ Nunung Nurazizah, "Pengembangan Perangkat Pembelajaran Pendidikan Keaksaraan Dasar Berbasis Kearifan Lokal Pada Komunitas Adat Terpencil (KAT) Suku Dayak Meratus," Jurnal Ilmiah Visi 13, no. 2 (December 2018): 127.

${ }^{5}$ Tiwi Etika, "Perjuangan Kritis Agama Kaharingan di Indonesia: Tantangan Berat dan Masa Depan Agama Asli Suku Dayak,” Jurnal Studi Kultural 6, no. 1 (January 2019): 1.
} 
berkembang dan mendapat tempat ibadah yang dinamakan Balai Basarah atau Balai Kaharingan, tempat beribadah kepada Sang Pencipta Ranying Hatalla Langit (Tuhan Yang Maha Esa). Pada tahun 2006 Kalimantan terdata 212 Balai Basarah. Agama Kaharingan juga mempunyai Kitab Suci yang disebut Panaturan dan buku-buku agama lain, seperti Talatah Basarah (Kumpulan doa), tawar (petunjuk tatacara meminta pertolongan Tuhan dengan upacara menabur beras), pemberkatan perkawinan, dan buku penyumpahan (untuk acara pengambilan sumpah/pengukuhan jabatan). ${ }^{6}$

Mereka juga merayakan hari keagamaan, mendirikan organisasi keagamaan untuk pembinaan umat mulai dari SD hingga perguruan tinggi, mengadakan Festival Tandak, seperti Musabaqah Tilawatil Quran dan pesta paduan suara gerejawi (Pesparawi), serta membangun komplek pemakam dan sanding. Sejak tahun 1980 mereka dimasukan sebagai penganut Hindu. Dengan dasar ini suku dayak sudah diperbolehkan mencantumkan agama Kaharingan dalam Kartu Tanda Penduduk. Dengan demikian, suku Dayak yang melakukan upacara perkawinan menurut adat Kaharingan, diakui pula pencatatan perkawinan tersebut oleh Negara. Hingga tahun 2007, badan pusat Statistik Kalimantan Tengah mencatat ada 223.349 orang menganut Kaharingan di Indonesia. Pada tanggal 20 April 1980 Kaharingan dimasukan kedalam agama Hindu Kaharingan. Organisasi alim ulama Hindu Kaharingan (MBAHK) pusatnya di Palangkaraya, Kalimantan Tengah.

\section{Metode}

Dalam artikel ini penulis menggunakan pendekatan kualitatif deskriptif . Dengan mengamati pelaksanaan upacara Tiwah melalui wawancara dan literatur yang ada, penulis mengkaji makna dalam upacara Tiwah tersebut yang kemudian disaring dengan metode mengadopsi, mengubah, dan membuah dan firman Tuhan sebagai tolak ukurnya. Setelah menemukan makna dalam upacara Tiwah tersebut, mengkontekstualisasikannya dan menggunakannya untuk menyampaikan Injil kepada masayarakat yang bersangkutan. Dengan literatur-literatur serta melihat dukungan dari buku tafsiran, penulis mengolah dan menyajikan hasil pembahasan dalam artikel ini.

\section{Hasil dan Pembahasan}

\section{Sekilas Tentang Upacara Tiwah dan Suku-Suku yang Melaksanakannya}

Abdul Helim And Unggun Tiara Syahriana dalam kepercayaan agama Hindu Kaharingan, kata tiwah berasal dari bahasa Sangiang yang berarti upacara penyucian, pembebasan roh untuk memperoleh hidup baru, jadi ritual tiwah ini dilaksanakan oleh agama tersebut karena dipercayai akan menghantar arwah kepada Ranying Hatalla langit yang akan menyucikan arwah untuk memperoleh hidup bersama dengan Ranying Hatalla kepada

${ }^{6}$ I Komang Widyana, "Pendidikan Agama Hindu Berbasis Kearifan Lokal Kaharingan Melalui Mata Kuliah Tawur Di Sekolah Tinggi Agama Negeri Tampung Penyang Palangka Raya," Dharmasakti 9, no. 2 (October 2018): 1. 
penyempurnaan, atau disebut penyempurnaan roh liau balawang panjang (unsur bapak) dan roh liau karahang tulang (unsur ibu). Tujuannya, dengan melaksanakan upacara tiwah ini kedua roh tersebut akan lebih suci, sehingga memperoleh penyatuan dengan Allah (Ranying Hatalla). ${ }^{7}$ Artinya bahwa Upacara Tiwah merupakan nama sebuah upacara penghantar kerangka jenazah ke tempat peristirahatan yang terakhir. Tradisi ini hanya dilakukan oleh suku dayak yang ada di Kalimantan Tengah. Upacara Tiwah yaitu prosesi menghantarkan roh leluhur sanak saudara yang telah meninggal dunia ke alam baka dengan cara menyucikan dan memindahkan sisa jasad dari liang kubur menuju sebuah tempat yang bernama Sandung/balai nyahu. Pelaksanaan upaca tiwah, ritual yang dilakukan suku dayak untuk bertujuan mengantar arwah menuju tempat asal (lewu tatau/ bisa disebut sorga) bersama Ranying Hatala (dewa tertinggi dalam kepercayaan Kaharingan).

Upacara adat Tiwah, merupakan upacara yang hanya dilakukan oleh warga Dayak Kalimantan Tengah. Tiwah merupakan upacara ritual kematian tingkat akhir bagi masyarakat suku Dayak di Kalimantan Tengah, khususnya dayak pedalaman penganut agama Kaharingan sebagai agama leluhur warga dayak. Saputri, dkk. mengatakan bahwa upacara Tiwah merupakan tradisi upacara masayarakat suku Dayak penganut agama Hindu Kaharingan. ${ }^{8}$ Upacara ritual ini merupakan kebahagian dan kehormatan bagi keluarga apabila telah melaksanakan upacara tiwah bagi keluarga yang telah meninggal dunia, karena mereka terlepas dari Pali dan perjanjian dengan roh keluarga yang meninggal keluarganya. Pali belum dalam kepercayaan Kaharingan adalah sebuah petaka besar, kesialan bagi keluarga Almarhum yang ditinggalkan dari pengaruh-pengaruh buruk yang menimpa keluarga, yang berakibat/berujung pada kematian. Jika keluarga tidak mentaati alur jalan adat tersebut sebelum sampai kepada pelaksanaan upaca tiwah selesai, maka petaka itu akan menimpa mereka, karena upacara tiwah itulah ritual terakhir menurut kepercayaan Kaharingan yang akan melepaskan, dan membebaskan keluarga yang ditinggalkan dari malapetaka di dunia nyata mereka. Upacara adat Tiwah dilaksanakan bertujuan sebagai ritual untuk meluruskan perjalanan roh atau arwah yang bersangkutan menuju Lewu Tatau (Surga - tempat Sangiang), sehingga bisa hidup tentram dan damai di alam Sang Kuasa.

\section{Upacara Tiwah dalam Agama Hindu Kaharingan}

\section{Pelaksanaan Upacara Tiwah}

Dalam tahap pelaksanaan, terdapat berbagai kegiatan yang cukup banyak yaitu diantaranya terdiri dari: proses menenung; proses manawur; mandawe malawas, baliang angiang bagawi sanding; mampandeng sapundu; munduk hanteran; munduk hanteran I; basir

\footnotetext{
${ }^{7}$ Abdul Helim and Unggun Tiara Syahriana, "Keikutsertaan Masyarakat Muslim Dalam Upacara Tiwah Agama Hindu Kaharingan Di Kota Palangka Raya,” Al-Qisthu: Jurnal Kajian Ilmu-ilmu Hukum 17, no. 2 (2019): 34-42.

${ }^{8}$ Claudya Ika Saputri, Deni Tri Ardianto, and Erandaru, "Perancangan Film Dokumenter Tradisi Keagamaan Upacara Tiwah Suku Dayak Di Kalimantan Tengah,” Jurnal DKV Adiwarna 1, no. 8 (2016): 1.
} 
munduk II; balian ngarahang tulang; dan memasukkan tulang ke dalam sandung. ${ }^{9}$ Pelaksanaan upacara tiwah ini juga dilakukan secara tradisional tanpa ada aturan-aturan yang mutlak secara tertulis. Hal tersebutlah yang menyebabkan secara teknis pelaksanaan upacara tiwah di setiap daerah berbeda. Namun hal itu tidaklah menjadi masalah, asalkan esensi dari upacara tersebut tidak hilang, yaitu menghantar para arwah ke surga agar dapat bersatu dengan Ranying Hattala. ${ }^{10}$

Tahap-Tahap Pelaksanaan Upacara Tiwah

Pelaksanaan upacara tiwah merupakan upacara yang dilandasi oleh kearifan lokal yang mana kearifan tersebut merupakan kearifan yang berkembang di masyarakat agama Hindu Kaharingan. Upacara tersebut juga merupakan suatu kewajiban bagi penganut agama Hindu Kaharingan sebagaimana yang dipesankan oleh Ranying Hatalla Langit (Tuhan) yang terdapat dalam kitab Panaturan. ${ }^{11}$ Mujiyono menjelaskan mengenai kesebelas tahap-tahap pelaksanaan upacara Tiwah sebagai berikut: ${ }^{12}$

\section{Menenung}

Orang-orang yang melakukan prosesi pada tahap ini ialah para Rohaniawan. Tahap ini merupakan sebuah prosesi pemanggilan roh-roh Sahur Parapah. Roh-roh Sahur Parapah ialah roh-roh yang mendapatkan suatu tugas khusus dari Tuhan (Ranying Hattala Langit) untuk memberi petunjuk serta melindungi orang-orang dari roh-roh jahat. Tujuan dari tahap ini ialah untuk mendapatkan petunjuk dari para leluhur agar keselamatan terjadi saat upacara Tiwah dilaksanakan dan acara dapat berjalan dengan baik serta para tamu yang menghadiri kegiatan tersebut merasa gembira.

\section{Manawur Mampakan Sahur}

Ritual ini merupakan ritual kelanjutan dari tahap sebelumnya.Pada tahap ini disediakan sebuah sesajian yaitu tiga ekor ayam yang mana ketiga ekor ayam tersebut digantung bersama tiga buah tombak dan ketupat. Hal tersebut dilakukan pada saat Basir mulai melakukan manawur dan manggantung sahur, mulai saat itu, ada sebuah pamali atau pantangan bagi keluarga anggota dan masyarakat yang menyaksikan upacara Tiwaha. Pada saat itu juga Rohaniawan akan memulai kegiatan sesuai dengan jadwal yang telah ditentukan.

\footnotetext{
${ }^{9}$ Abdul Helim and Tiara Syahriana, "Keikutsertaan Masyarakat Muslim Dalam Upacar Tiwah Agama Hindu Kaharingan Di Kota Palangkaraya,” Al-Qisthu: Jurnal Kajian Ilmu-ilmu Hukum 17, no. 2 (December 2019): 36.

${ }^{10}$ Timotius Nusan, Tiwah Dan Perlengkapannya (Palangkaraya: Departemen Pendidikan dan Kebudayaan Provinsi Kalimantan Tengah, 1997), 1.

${ }^{11}$ Sanawiah and M. Raymon Abdalla, "Hukum Keikutsertaan Warga Dayak Ngaju Muslim Dalam Pelaksanaan Upacara Tiwah,” Jurnal Hadratul Madaniyah 5, no. 2 (December 2018): 3.

${ }^{12}$ Mujiyono, "Upacara Tiwah Pada Masyarakat Hindu Kaharingan Di Palangka Raya (Perspektif Teologi Hindu)" (Institut Hindu Dharma Negeri Denpasar, 2006), 148-163.
} 


\section{Balian Baramu Paramun Balian Baramu Paramun}

Tahap ini merupakan tahap pembacaan doa sebagai sebuah pemberitahuan kepada Sangiang Rawing Tempun bahwa ada arwah baru yang akan diantarkan melalui tiwah dan juga sebagai permohonan kepada Sangiang agar memberkati upacara Tiwah tersebut.

\section{Balian Mangkang Huma Ain Upun Gawe Prosesi}

Tahap ini merupakan sebuah permohonan doa untuk melakukan penelusuran kembali terhadap liau (roh) yang mana roh tersebut berada di dalam kuasa Sangiang Rawing Tempun Telun. Kemudian ada permohonan terhadap roh tersebut untuk diadakan korban dan penyempurnaan dengan mengadakan upacara tiwah dengan tujuan menyatu kembali pada Ranying Hatalla di Lewu Tatau.

\section{Nalampas Nalampas}

Tahap ini merupakan prosesi pengangkatan tulang manusia yang meninggal tersebut dari kubur orang yang akan ditiwahkan. Para penyelenggara Tiwah dalam tahap ini juga berangkat ke kuburan untuk menaburkan beras putih, beras kuning, dan beras merah yang telah bercampur dengan darah babi di atas kubur, dan kemudian menebaskan mandau (senjata daerah Kalimantan) ke tanah kuburan dan kemudian kuburan mulai digali dan raung (peti mati) dibuka untuk mengangkat atau mengambil semua tulang-belulang. Tulang-belulang ini dibersihkan dengan air sabun dan dimasukkan ke dalam peti yang telah disediakan. Setiap peti hanya dibolehkan untuk satu tulang orang, kecuali jika tulang itu dari pasangan suami-isteri. ${ }^{13}$

\section{Mandawen Malawas, Balian Sangiang Bagawi Sandung}

Ada tiga prosesi dalam tahap ini yaitu balian, penyucian Sandung, dan ucapan syukur. Ucapan syukur tentang terselesainya pembuatan Sandung yang akan digunakan untuk menyimpan tulang.

\section{Nganihi, Mampendeng Sapundu}

Semua anggota keluarga yang mengikuti upacara tiwah dengan berkumpul di depan Kanihi, sebuah tempat Sangkairaya yang didirikan sebagai pusat pelaksanaan tiwah. Sebagian dari anggota tiwah memasak beras ketan di dalam ruas bambu yang juga disebut nasi lemang, ayam kampung, dan babi. Kegiatan memasakn ini dilakukan di waktu malam hari yang mana malam ini disebut sebagai malam kanihi, yaitu malam persembahan sesajian. Pada tahap ini dibuatah suatu pandang bawui, yaitu sebuah tempat untuk menaruh babi sebagai hewan korban. Kemudian didirikan juga Sapundu, suatu tiang dari kayu besi yang bermotif manusia sebagai tempat untuk mengikat kerbau atau sapi yang akan dikorbankan.

\footnotetext{
${ }^{13}$ Helim and Syahriana, "Keikutsertaan Masyarakat Muslim Dalam Upacar Tiwah Agama Hindu Kaharingan Di Kota Palangkaraya," 38.
} 
Setelah kerbau atau sapi diikat dan siap ditombak pada Sapundu, anggota keluarga dalam upacara tiwah kemudian menabur beras kuning pada hewan korban sebagai permohonan doa sebagai simbol persembahan kepada Ranying Hatalla dan roh para leluhur. Pada tahap ini juga dilakukan tarian sakral kematian (nganjen) dan tarian rakyat (manase) dengan mengelilingi korban yang telah diikat pada Sapunda dengan perhitungan waktu tertentu. Tarian ini juga merupakan simbol persembahan hewan korban kepada Tuhan dan roh para leluhur.

\section{Munduk Hanteran (Tabuh I)}

Munduk yang berarti duduk dan Hanteran yang bearti Basir senior yang disebut sebagai Rohaniwan utama. Rohaniawan utama inilah sebagai pihak yang bertanggung jawab dalam upacara tiwah. Dalam pelaksanaannya, Basir senior duduk untuk melaksanakan balian, yaitu pembacaan doa sebagai penghantar para arwah yang ditiwahkan menuju lewu tatau. Munduk Hanteran dilakukan di malam hari setelah selesai melaksanakan nganihi dan mendirikan Sapundu. Setelah keesokkan harinya diadakan tabuh I. Pada malam tersebut, semalam suntuk keluargayang hadir berdoa kepada Tuhan dan leluhur tanpa makan, minum atau keluar dari tempat tersebut.

\section{Basir Munduk (Tabuh ke II)}

Basir Munduk merupakan kegiatan yang mengantarkan arwah dengan membaca doa berupa lagu balian yang dilakukan oleh Basir. Sebelum mereka melantunkan lagu balian, mereka diberi isyarat balian seperti emas, perak, uang logam, lilis lamiang sebagai persyaratan liau balawang panjang (roh) ke lewu tatau (surga).

\section{Balian Ngarahang Tulang}

Tahap ini merupakan tahap kelanjutan dari tahap sebelumnya, yaitu setelah tulang diupacarakan dengan tata cara Kaharingan. Upacara yang dilakukan sama pelaksanaan basir munduk. Setelah itu dilanjutkan dengan memanggil dan memohon kepada Duhung Mama Tandang agar datang dan mengambil liau karahang tulang arwah mereka yang ditiwah.

\section{Memasukkan Tulang ke Sandung}

Pelaksanaan ini disebut pula nyakean. Tahap ini diiringi dengan ritual-ritual tertentu. Dalam tahap ini, tulang orang mati yang ditiwah kemudian diletakkan di atas kain yang telah disiapkan yang mana kain tersebut mengarah ke Sandung. Dari pihak keluarga juga dalam tahap ini memberikan penghormatan untuk terakhir kalinya kepada keluarga yang ditiwahkan dan para Rohaniwan memohon pada Tuhan supaya menyediakan tempat bagi arwah yang ditiwahkan agar masuk ke Sandung. 


\section{Makna dan Tujuan Upacara Tiwah}

Menurut Wati, tujuan dari upacara tiwah adalah kedua roh yang dilakukan ketiwahan tersebut akan lebih suci dalam penyatuan dengan Yanying Hatalla. ${ }^{14}$ Kemudian Mujitono menjelaskan bahwa makna tiwah yang terkandung dalam kitab Panaturan agama Hindu Kaharingan yaitu sebagai jalan ataupun tata cara arwah untuk kembali dan datang menyatu dengan Tuhan. ${ }^{15}$ Seorang tokoh Hindu Kaharingan, yaitu Thian Agan mengatakan bahwa tiwah merupakan suatu upacara ritual kematian tingkat akhir yang bertujuan supaya anggota keluarga yang ditiwahkan memperoleh kelahiran baru dan diantar menuju lewu tatau (surga yang kekal abadi). ${ }^{16}$ Senada dengan apa yang dikatakan oleh Riwut bahwa upacara tiwah terbesar yang merupakan upacara yang dilakukan untuk menghantarkan jiwa yang telah meninggal menuju lewu tatau (surga). Upacara tiwah juga upacara yang melaksanakan kegiatan pengorbanan binatang, yaitu kerbau ${ }^{17}$ Dari pendapat beberapa tokoh tersebut, dapat disimpulkan bahwa upacara tiwah merupakan upacara untuk menghormati anggota yang telah meninggal yang ditiwahkan yang bertujuan untuk menghantar arwah tersebut agar mendapat suatu kelahiran baru menuju kesempurnaan di surga.

\section{Pemaknaan Upacara Tiwah Sebagai Pendekatan Penginjilan Kontekstual}

Packer mengatakan bahwa Injil merupakan berita tentang Allah. Artinya bahwa di dalam pemberitaan Injil mengandung berita tentang siapa Dia, apa karakter-Nya, apa ciptaanNya. ${ }^{18}$ Setiap pemberitaan Injil, Yesus menjadi pusat dari segalanya. Hal tersebut tentunya juga tidak mengabaikan objek yang mendengar tentang Injil tersebut, yaitu manusia. Tomatala mengatakan bahwa target primer dan sasaran dalam penginjilan ialah manusia. ${ }^{19}$ Selain itu, Injil berperan untuk memperbaiki paradigma dan praktik yang keliru dalam kebudayaan tersebut. Kesalahpahaman tentang praktik keagamaan mengarah kepada persepsi yang keliru. $^{20}$ Jadi, melalui budaya yang ada dalam suatu suku tertentu, Injil dapat diberitakan dengan tujuan untuk mengubah paradigma masyarakat tersebut.

Dalam upaya pemberitaan Injil, pendekatan kontekstual relevan dengan penginjilan dalam suatu budaya tertentu. Kobong menjelaskan bahwa penginjilan kontekstual memberikan suatu tekanan kepada pemberitaan Injil dengan penghayatan yang memberi sentuhan terhadap penerima Injil. ${ }^{21}$ Lebih lanjut Budiman mengatakan bahwa penginjilan

\footnotetext{
${ }^{14}$ Wati, "Peranan Basir Duhung Handepang Telun Dalam Upacara Tiwah Menurut Ajaran Agama Hindu Kaharingan Di Desa Tarantang Kecamatan Mantangai Kabupaten Kapuas" (Sekolah Tinggi Agama Hindu Negeri Tampung Penyang, 2006), 12.

${ }^{15}$ Mujiyono, "Upacara Tiwah Pada Masyarakat Hindu Kaharingan Di Palangka Raya (Perspektif Teologi Hindu),, 25.

${ }^{16}$ Helim and Syahriana, "Keikutsertaan Masyarakat Muslim Dalam Upacar Tiwah Agama Hindu Kaharingan Di Kota Palangkaraya," 35.

${ }^{17}$ Tjilik Riwut, Kalimantan Membangun Dan Kebudayaan (Yogyakarta: NR Publishing, 2007), 254.

${ }^{18}$ J.I. Packer, Penginjilan Dan Kedaulatan Allah (Surabaya: Momentum, 2014), 47.

${ }^{19}$ Yakob Tomatala, Teologi Misi (Jakarta: YT Leadership Foundation, 2003), 33.

${ }^{20}$ Fransiskus Irwan Widjaja and Noh Ibrahim Boiliu, Misi Dan Pluralitas Keyakinan Di Indonesia (Yogyakarta: PMBR ANDI, 2019), 117.

${ }^{21}$ Th. Kobong, Iman Dan Kebudayaan (Jakarta: BPK Gunung Mulia, 24), 24.
} 
kontekstual ialah suatu cara menyampaikan Injil melalui penyesuaian diri dengan budaya setempat agar Injil tersebut menjadi relevan bagi si penerima. ${ }^{22}$ Dengan demikian, penginjilan kontekstual pada akhirnya akan memberikan suatu rasa solidaritas terhadap semua orang dalam hal ketaatan kepada Tuhan. ${ }^{23}$ Melalui pendekatan penginjilan kontekstual, penulis memberkan tiga kontekstualisasi makna upacar Tiwah ke dalam penginjilan, yang mana penulis memakai, mengubah, dan membuang budaya sesuai dengan standar firman Tuhan dan tidak mengubah makna Injil itu sendiri.

\section{Yesus Sebagai Korban dalam Upacara Tiwah}

Setelah diketahui dari makna upacara tiwah dalam agama Hindu Kaharingan serta kaitannya dengan korban keselamatan, penulis mengadopsi dari pengajaran Hindu Kaharingan yang mengacu kepada korban. Dalam agama Hindu Kaharingan, penganutnya masih memegang konsep korban yang serupa dengan ajaran di dalam Alkitab, secara khusus dalam Perjanjian Lama, sehingga manusia yang telah meninggal dapat diterima dan damai bersama dengan Ranying Hatalla (Tuhan). Untuk meluruskan konsep penyucian diri yang mengarah kepada keselamatan di dalam paham Hindu Kaharingan, korban binatang yang dilakukan dalam upacara Tiwah yaitu potong kerbau di tiang sapundu/patung. Penulis mengambil dasar Alkitab sebagai jembatan penginjilan kontekstual, yaitu Yesus sebagai Anak Kerbau Allah, yang diberikan Bapa sebagai korban penyucian yang sempurna yang oleh-Nya manusia dapat diselamatkan (Kis. 4:12). Ia benar-benar memberikan hidup yang kekal (Yoh. 14:6)."24 Dengan demikian, Allah melalui Yesus Kristus menjadi pusat iman yang menyelamatkan. ${ }^{25}$ Pengorbanan yang sempurna dan yang paling penting telah digenapi oleh Kristus, " yang telah menyelamatkan umat dari murka yang akan datang” (I Tes. 1:10). Melalui dasar ayat Alkitab ini, penulis memberikan pemaknaan baru dari makna upacara Tiwah dengan menceritakan penebusan dan korban yang sempurna, yaitu Kristus Anak Kerbau Allah sebagai satu-satunya Penebus dan Juruselamat Manusia. Hanya melalui Dia semua manusia yang berdosa dapat beroleh keselamatan dan hidup yang kekal. Pendekatan ini merupakan salah satu pendekatan yang dapat digunakan dalam upaya kontekstualisasi.

\section{Yesus Sebagai Jalan Menuju "Lewu Tatau”}

Salah satu makna penting yang telah dibahas di pembahasan sebelumnya tentang makna upacara tiwah, yaitu untuk menghantarkan arwah yang ditiwahkan menuju lewu tatau. Tujuan ini merupakan tujuan utama dari upacara tiwah. Melalui tujuan tersebut, dapat dikontekstualisasikan dalam konteks penginjilan yaitu Yesus Kristus sebagai jalan menuju lewu tatau. Dalam Yohanes 14:6 mengatakan bahwa Yesuslah jalan kebenaran dan jalan

\footnotetext{
${ }^{22}$ R.L. Budiman, Pelayanan Lintas Budaya Dan Kontekstualisasi (Jakarta: BPK Gunung Mulia, n.d.), 6.

${ }^{23}$ David J. Hesselgrave and Edward Rommen, Kontekstualisasi: Makna, Metode Dan Model (Jakarta: BPK Gunung Mulia, 1996), 52.

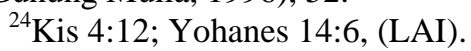

${ }^{25}$ John Piper, Jadikan Semua Bangsa Bersukacita (Bandung: Lembaga Literatur Baptis, 2001), 193.
} 
kehidupan. Tidak ada seorang pun yang dapat datang kepada Bapa kalau tidak melalui Kristus. Dalam konteks ini, Yesus sedang menjelaskan bahwa diri-Nya akan pergi ke rumah Bapa untuk menyediakan tempat bagi murid-murid-Nya. Yesus juga menjelaskan bahwa ke mana Ia pergi, murid-murid-Nya tidak tahu jalan ke situ. Kemudian Thomas bertanya bagaimana murid-murid-Nya dapat pergi ke tempat yang Yesus maksud. Yesus menjelaskan bahwa diri-Nya sebagai jalan menuju rumah Bapa. Henry juga menegaskan bahwa Yesus sebagai kebenaran berarti Yesus sebagai Pribadi yang menuntun orang yang percaya kepadaNya menuju kehidupan, dan Yesus sebagai hidup ialah Yesus sebagai ujung atau akhir dari jalan menuju kehidupan kekal. ${ }^{26}$ Dalam Yohanes 10:9 juga menjelaskan bahwa Yesuslah pintu dan barangsiapa masuk melalui Yesus, ia akan hidup. Melalui dasar Alkitab tersebut, kemudian ditarik kepada konsep pemahaman dalam ajaran Hindu Kaharingan tentang makna upacara tiwah bahwa Yesus adalah jalan menuju ke lewu tatau. Tidak ada jalan lain, hanya melalui Yesus. Dijelaskan juga oleh Ajith Fernando bahwa Yesus sebagai berita misi Allah, yang benar-benar memberikan jalan untuk ke surga. ${ }^{27}$ Kemudian Riderbos juga mengatakan bahwa Yesus benar-benar memberikan jawaban terhadap para murid, dengan mengatakan bahwa Dia adalah jalan untuk kesurga. ${ }^{28}$

Yesus Sebagai Pengantara antara Manusia dan "Ranying Hatalla"

Di dalam upacara tiwah ada yang disebut sebagai Hanteran, yaitu Basir senior yang bertugas untuk melaksanakan pembacaan doa atau yang disebut dengan istilah balian. Hanteran ini ialah orang yang paling bertanggung jawab atas pelaksanaan upacara tiwah. Rohaniawan utama (hanteran) ini sebagai pengantara antara anggota atau umat yang ikut upacara tiwah serta arwah yang ditiwahkan dengan Ranying Hatalla. Jelas dalam kepercayaan Kristen mengatakan bahwa Yesus sebagai pengantara antara manusia dengan Allah. Dalam 1 Timotius 2:5-6 mengatakan bahwa "Karena Allah itu esa dan esa pula Dia yang menjadikan pengantara antara Allah dan manusia, yaitu manusia Kristus Yesus, yang telah menyerahkan diri-Nya sebagai tebusan bagi semua manusia..." kemudian Carson dkk, mengatakan keunikan pengantaraan Yesus Kristus ditunjukan dengan menghubungkan penyerahan diriNya sendiri sebagai tebusan. $^{29}$

Rasul Yohanes juga mengatakan dalam 1 Yohanes 2:1 bahwa “...kita mempunyai seorang pengantara pada Bapa, yaitu Yesus Kristus...” Demikian pula dalam upacara tiwah mengenai rohaniawan utama yang sebagai pengantara antara umat dengan Ranying Hatalla, ditarik dalam konsep penginjilan, Yesus sebagai pengantara yang sempurna antara manusia dengan Allah. Dalam Ibrani 6: 20 Yesus sudah membuka jalan bagi manusia dan menjadi

\footnotetext{
${ }^{26}$ Matthew Henry, Tafsiran Matthew Henry: Yohanes 12-21 (Surabaya: Momentum, 2007), 3528.

${ }^{27}$ Ajith Pernando, Allah Tritunggal Dan Misi (Jakarta: Yayasan Komunikasi Bina Kasih/OMF, 2015), 37.

${ }^{28}$ Herman N. Ridderbos, Injil Yohanes: Suatu Tafsiran Teologis (Surabaya: Momentum, n.d.), 536.

${ }^{29}$ D.A. Carson et al., Tafsiran Alkitab Abad Ke-21: Matius-Wahyu (Jakarta: Yayasan Komunikasi Bina Kasih/OMF, 2017), 554.
} 
Imam Besar untuk selama-lamanya seperti Melkisedek. ${ }^{30}$ Hal tersebut nyata bahwa Yesus Kristus adalah Imam Besar yang menjadi pengantara bagi manusia dengan Allah.

\section{Kesimpulan}

Upacara tiwah dalam agama Hindu Kaharingan merupakan kegiatan yang mengandung makna yang unik. Mulai dari persiapan hingga tahap pelaksanaannya tersirat makna-makna yang penting bagi penganut agama Hindu Kaharingan. Dengan memahami konsep dan makna dalam upacara tiwah ini, penulis menjadikannya sebagai media kontekstualisasi untuk menyampaikan Injil. Dalam pembahasan ini, ada tiga hal yang penulis amati dan kontekstualisasikan tanpa mengubah makna dari penginjilan itu sendiri dalam menyampaikan Injil, yaitu: Yesus sebagai korban yang sempurna; Yesus sebagai jalan menuju lewu tatau; dan Yesus sebagai pengantara antara manusia dan Allah. Melalui pemahaman dan pengadopsian budaya tersebut, orang Kristen dapat menyampaikan Injil dengan worldview yang dipahami oleh umat Hindu Kaharingan.

\section{Rujukan}

Brill, J.Wesley. Tafsiran Surat Ibrani. Bandung: Yayasan Kalam Hidup, 2004.

Budiman, R.L. Pelayanan Lintas Budaya Dan Kontekstualisasi. Jakarta: BPK Gunung Mulia, n.d.

Carson, D.A., R.T. France, J.A. Motyer, and G.J. Wenham. Tafsiran Alkitab Abad Ke-21: Matius-Wahyu. Jakarta: Yayasan Komunikasi Bina Kasih/OMF, 2017.

Etika, Tiwi. "Perjuangan Kritis Agama Kaharingan di Indonesia: Tantangan Berat dan Masa Depan Agama Asli Suku Dayak.” Jurnal Studi Kultural 6, no. 1 (January 2019): 1-12. Helim, Abdul, and Tiara Syahriana. "Keikutsertaan Masyarakat Muslim Dalam Upacar Tiwah Agama Hindu Kaharingan Di Kota Palangkaraya." Al-Qisthu: Jurnal Kajian Ilmuilmu Hukum 17, no. 2 (December 2019): 34-42.

Henry, Matthew. Tafsiran Matthew Henry: Yohanes 12-21. Surabaya: Momentum, 2007. Hesselgrave, David J., and Edward Rommen. Kontekstualisasi: Makna, Metode Dan Model. Jakarta: BPK Gunung Mulia, 1996.

Kobong, Th. Iman Dan Kebudayaan. Jakarta: BPK Gunung Mulia, 24.

Mahin, Marko. “Kaharingan: Dinamika Agama Dayak Di Kalimantan Tengah.” Universitas Indonesia, 2009.

Mujiyono. "Upacara Tiwah Pada Masyarakat Hindu Kaharingan Di Palangka Raya (Perspektif Teologi Hindu).” Institut Hindu Dharma Negeri Denpasar, 2006.

Nasruddin, dkk. Kearifan Lokal Di Tengah Modernisasi. Jakarta: Pusat Penelitian dan Pengembangan Kebudayaan Badan Pengembangan Sumber Daya Kebudayaan dan Pariwisata Kementerian Kebudayaan dan Pariwisata Republik Indonesia, 2011.

\footnotetext{
${ }^{30}$ J.Wesley Brill, Tafsiran Surat Ibrani (Bandung: Yayasan Kalam Hidup, 2004), 106.
} 
Nugraha, Agung. Rindu Ladang: Perspektif Perubahan Masyarakat Desa Hutan. Tangerang: Wana Aksara, 2009.

Nurazizah, Nunung. "Pengembangan Perangkat Pembelajaran Pendidikan Keaksaraan Dasar Berbasis Kearifan Lokal Pada Komunitas Adat Terpencil (KAT) Suku Dayak Meratus.” Jurnal Ilmiah Visi 13, no. 2 (December 2018): 123-134.

Nusan, Timotius. Tiwah Dan Perlengkapannya. Palangkaraya: Departemen Pendidikan dan Kebudayaan Provinsi Kalimantan Tengah, 1997.

Packer, J.I. Penginjilan Dan Kedaulatan Allah. Surabaya: Momentum, 2014.

Pernando, Ajith. Allah Tritunggal Dan Misi. Jakarta: Yayasan Komunikasi Bina Kasih/OMF, 2015.

Piper, John. Jadikan Semua Bangsa Bersukacita. Bandung: Lembaga Literatur Baptis, 2001.

Ridderbos, Herman N. Injil Yohanes: Suatu Tafsiran Teologis. Surabaya: Momentum, n.d.

Riwut, Tjilik. Kalimantan Membangun Dan Kebudayaan. Yogyakarta: NR Publishing, 2007.

Sanawiah, and M. Raymon Abdalla. "Hukum Keikutsertaan Warga Dayak Ngaju Muslim Dalam Pelaksanaan Upacara Tiwah.” Jurnal Hadratul Madaniyah 5, no. 2 (December 2018): 1-12.

Saputri, Claudya Ika, Deni Tri Ardianto, and Erandaru. "Perancangan Film Dokumenter Tradisi Keagamaan Upacara Tiwah Suku Dayak Di Kalimantan Tengah.” Jurnal DKV Adiwarna 1, no. 8 (2016): 1-7.

Tomatala, Yakob. Teologi Misi. Jakarta: YT Leadership Foundation, 2003.

Wati. "Peranan Basir Duhung Handepang Telun Dalam Upacara Tiwah Menurut Ajaran Agama Hindu Kaharingan Di Desa Tarantang Kecamatan Mantangai Kabupaten Kapuas.” Sekolah Tinggi Agama Hindu Negeri Tampung Penyang, 2006.

Widjaja, Fransiskus Irwan, and Noh Ibrahim Boiliu. Misi Dan Pluralitas Keyakinan Di Indonesia. Yogyakarta: PMBR ANDI, 2019.

Widyana, I Komang. "Pendidikan Agama Hindu Berbasis Kearifan Lokal Kaharingan Melalui Mata Kuliah Tawur Di Sekolah Tinggi Agama Negeri Tampung Penyang Palangka Raya." Dharmasakti 9, no. 2 (October 2018): 101-113. 